\title{
Perencanaan Strategik Sistem Informasi Pengembangan Usaha UD Vier 57 Sehat Bergizi
}

\author{
Strategic Information System Planning to Increase The Competitive Advantage of \\ UD Vier 57 Sehat Bergizi
}

\author{
Rizki Fadli $^{*}$, Muhammad Syamsun², dan Wini Trilaksani ${ }^{3}$ \\ ${ }^{1}$ Kementerian Kelautan dan Perikanan \\ Gedung Mina Bahari I, Jl. Medan Merdeka Timur No. 16, Gambir, Jakarta Pusat 10110 \\ ${ }_{2}^{2}$ Program Studi Pengembangan Industri Kecil Menengah, Sekolah Pascasarjana IPB \\ Jl. Raya Pajajaran, Kampus IPB Baranangsiang, Bogor 16144 \\ ${ }^{3}$ Departemen Teknologi Hasil Perairan, Fakultas Perikanan dan Ilmu Kelautan \\ Jl. Lingkar Akademik, Kampus IPB Darmaga, Bogor 16680
}

\begin{abstract}
ABSTRAK
Perusahaan kecil, menengah hingga perusahaan besar di era komputerisasi sekarang ini dituntut agar bisa memuaskan kebutuhan para konsumennya. Adanya internet saat ini memungkinkan konsumen setiap saat siap menerima informasi dari berbagai penjuru dunia. Penggunaan internet telah digunakan oleh UD Vier 57 Sehat Bergizi pada tahun 2016. Dampak dari penggunaan website tersebut belum memengaruhi peningkatan produksi dan jumlah agen perusahaan secara nyata. Tujuan penelitian: (1) mengidentifikasi penerapan sistem informasi yang sedang berjalan pada UD Vier 57 Sehat Bergizi, (2) menganalisis kebutuhan penerapan sistem informasi (SI) perusahaan untuk meningkatkan keunggulan kompetitif perusahaan, dan (3) mengidentifikasi dan merekomendasikan strategi pengembangan usaha yang tepat. Analisis data yang digunakan dalam penelitian ini adalah analisis rantai nilai (value chain analysis-VCA), analisis lima kekuatan Porter (five competitive forces porter) dan analisis SWOT (Strengths, Weakness, Opportunities dan Threats). Contoh yang digunakan adalah dua orang narasumber. Penelitian ini menunjukkan pemanfaatan teknologi informasi (TI) pada UD Vier 57 Sehat Bergizi belum maksimal dalam bidang pemasaran. Skor IFE 3,098 menunjukkan kekuatan yang dimiliki UD Vier 57 Sehat Bergizi dapat mengatasi kelemahan dengan cukup baik dan skor EFE 2,629 menunjukkan UD Vier 57 Sehat Bergizi cukup baik dalam merespon peluang dan meminimalisasi ancaman. Perpaduan skor IFE dan EFE dalam matriks IE terletak pada kuadran IV, yaitu grow and build. Strategi yang cocok adalah strategi intensif (penetrasi pasar, pengembangan pasar dan pengembangan produk). Analisis SWOT diperoleh enam rumusan alternatif strategi. Perhitungan matriks Quantitative Strategic Planning diperoleh strategi yang paling menarik untuk diterapkan, yaitu meningkatkan upaya pemasaran secara intensif dan efisien melalui media online.
\end{abstract}

Kata kunci: perencanaan strategi, sistem informasi, teknologi informasi

\section{ABSTRACT}

Small, medium to large companies in the computerization era is required to satisfy the customer needs. The existence of internet allow customer to receive information over the world. internet usage has been used by UD Vier 57 Sehat Bergizi in 2016, but there are no significant impact on production or number of agents. This study has three main objectives that include the following: (1) to identify the implementation of information system in UD Vier 57 Sehat Bergizi, (2) to analyze the needs of information system to improve the company's competitive advantages and (3) to identify and recommend appropriate business development strategy. Analysis data was used in this study are value chain analysis, five competitive forces porter and SWOT (Strengths, Weakness, Opportunities dan Threats)

\footnotetext{
*) Korespondensi:

Gedung Mina Bahari I Lt.5, Jl. Medan Merdeka Timur No. 16, Gambir, Jakarta Pusat;

email: rizkip2hp@gmail.com
} 
analysis. Sample that used in this research was 2 respondents. This study showed that the use of information technology in UD Vier 57 Sehat Bergizi is not optimal. IFE score was 3,098 described that the strength owned by UD Vier 57 Sehat Bergizi can overcome it weakness fairly enough. EFE score was 3,339 described that UD Vier 57 Sehat Bergizi was good enough in responding the opportunity and minimize the threat. Score combination of EFE and IFE in IE matrix located in quadrant IV, grow and build. Strategy that fit to UD Vier 57 Sehat Bergizi was intensive strategy (market penetration, market development and product development). SWOT analysis produces 6 alternative strategy formula. Based on calculation in Quantitative Strategic Planning matrix, the most interesting strategy produced was increase marketing intensively and efficiently through online media.

Key words: information system, information technology, strategy planning

\section{PENDAHULUAN}

Perusahaan kecil, menengah hingga perusahaan besar pada era komputerisasi sekarang ini dituntut untuk bisa memuaskan kebutuhan para konsumennya. Hal ini disebabkan maraknya persaingan antar perusahaan yang memiliki produk sejenis atau serupa. Berbagai cara diupayakan untuk meningkatkan daya jual dari produk-produk dan mempertahankan eksistensi dari perusahaan tersebut. Menurut data yang dirilis oleh Asosiasi Penyelenggara Jasa internet Indonesia (APJII), jumlah pengguna internet pada tahun 2015 mengalami kenaikan 12\% sebesar 93,5 juta. Angka tersebut naik dari 88,1 juta di tahun 2014 (APJII, 2015). internet didefinisikan sebagai jaringan luas komputer dengan perizinan saling berkoneksi antara satu dengan yang lainnya untuk menyebarluaskan dan membagikan digital files, serta memperpendek jarak antar negara. Internet memiliki berbagai macam teknologi, seperti website, transfer file, email, jaringan pertemanan, forum, mailing list, dan sebagainya (Yunus, 2011). Adanya internet saat ini memungkinkan konsumen setiap saat siap menerima informasi dari berbagai penjuru dunia. Hal yang tidak pernah terbayangkan oleh para pemasar dan pelaku bisnis. Hal ini menjadi tantangan tersendiri bagi para pemasar.

Perusahaan yang ingin tetap bertahan dan berkembang pada era Information and Communications Technologies (ICT) sekarang ini perlu mengimplementasikan sistem informasi (SI) yang didukung oleh perkembangan infrastruktur teknologi informasi (TI), karena pada dasarnya perkembangan yang terjadi dalam bidang SI/TI tersebut berdampak positif terhadap berbagai aktivitas bisnis di dalam perusahaan, maupun aktivitas bisnis dengan pihak luar perusahaan.

Menurut Laudon (2004), strategi sistem informasi adalah sistem komputer pada setiap level yang ada pada organisasi yang mengubah tujuan, operasi, produk, pelayanan, atau hubungan antar lingkungan untuk membantu organisasi mengumpulkan keuntungan yang kompetitif. Turban (2005) menyatakan strategi informasi adalah sistem yang membantu sebuah organisasi untuk mendapatkan keuntungan kompetitif melalui kontribusinya terhadap strategi tujuan dari organisasi dan atau kemampuan untuk meningkatkan performa dan produktifitas secara nyata. Perencanaan strategis (Renstra) SI/TI merupakan proses identifikasi portfolio aplikasi sistem informasi berbasis komputer (SIBK) yang akan mendukung organisasi dalam pelaksanaan rencana bisnis untuk merealisasikan tujuan bisnisnya. Renstra SI/TI mempelajari pengaruh SI/TI terhadap kinerja bisnis dan kontribusi bagi organisasi dalam memilih langkah-langkah strategik. Selain itu, Renstra SI/TI menjelaskan berbagai alat, teknik dan kerangka kerja bagi manajemen untuk menye-laraskan strategi SI/TI dengan strategi bisnis, bahkan digunakan untuk mencari kesempatan baru melalui penerapan teknologi inovatif (Ward dan Peppard, 2002).

Hampir seluruh jenis usaha, baik skala besar maupun skala kecil saat ini memanfaatkan TI dengan tujuan peningkatan laba ataupun peningkatan pelayanan. Salah satunya UD Vier 57 Sehat Bergizi, produsen olahan daging sapi (baso) yang mulai memproduksi skala rumah tangga pada tahun 2013 untuk dikonsumsi kalangan terbatas. Seiring dengan meningkatnya permintaan, Baso 57 mulai diproduksi massal pada Tahun 2015. Berdasarkan penelitian yang dilakukan oleh Guna dan Karyono (2011) mengenai Renstra SI/TI pada Usaha Kecil Menengah (UKM) berbasis EBusiness dinyatakan untuk membangun UKM berbasis e-business diperlukan konsep yang baik, sehingga tahap implementasi dapat memberikan keuntungan bagi UKM. Penggunaan internet telah digunakan oleh UD Vier 57 Sehat Bergizi pada 
tahun 2016 melalui website http://www.baso57kuahsehat.com. Dampak dari penggunaan website tersebut belum memengaruhi peningkatan produksi dan jumlah agen perusahaan secara nyata (Tabel 1).

Tabel 1. Produksi baso 57 kuah sehat

\begin{tabular}{ccc}
\hline Tahun & $\begin{array}{c}\text { Rerata Jumlah Produksi } \\
\text { (Kemasan/Bulan) }\end{array}$ & $\begin{array}{c}\text { Jumlah Agen } \\
\text { (Orang) }\end{array}$ \\
\hline 2013 & 270 & 16 \\
2014 & 270 & 18 \\
2015 & 300 & 18 \\
2016 & 330 & 22 \\
\hline
\end{tabular}

Pemanfaatan internet dalam pengembangan bisnis memerlukan konsep yang baik dan kompetensi dari sumber daya manusia dalam perusahaan untuk meningkatkan jumlah agen dan konsumen. Penelitian ini bertujuan: (1) mengidentifikasi penerapan SI yang sedang berjalan pada UD. Vier 57 Sehat Bergizi, (2) menganalisis kebutuhan penerapan SI perusahaan untuk meningkatkan keunggulan kompetitif perusahaan, (3) mengidentifikasi dan merumuskan strategi pengembangan usaha yang tepat berdasarkan faktor internal dan eksternal lingkungan perusahaan.

\section{METODE PENELITIAN}

Penelitian dilaksanakan di UD Vier 57 Sehat Bergizi, Jalan Cendrawasih Raya Komplek Antilope Cempaka Residence No. A5, Jaticempaka, Pondok Gede, Kota Bekasi pada bulan November sampai Desember 2016.

Data yang dikumpulkan pada penelitian ini adalah data primer dan sekunder. Pengumpulan data primer dilakukan dengan mengajukan kuesioner dan wawancara. Kuesioner berisi daftar pertanyaan/pernyatan kepada responden dengan harapan responden akan memberikan respon atas daftar pertanyaan. Pengumpulan data sekunder dilakukan dengan mengidentifikasi kebutuhan data sekunder dalam penelitian ini. Data sekunder yang dimaksudkan adalah informasi yang mendukung tentang struktur organisasi dan data yang berkaitan dengan penelitian. Contoh penelitian diperoleh secara purposive, dengan pertimbangan wewenang dan kesediaan waktu responden. Responden terdiri dari satu orang direktur dan satu orang wakil direktur.

Dalam hal ini penulis melakukan penelitian dengan metode Ward dan Peppard, Metode Perencanaan Strategi SI/TI versi Ward dan
Peppard merupakan metode yang komprehensif, dimana metode ini terlebih dahulu dimulai dari kegiatan assesment dan pemahaman terhadap situasi saat ini baik terhadap lingkungan bisnis maupun lingkungan SI/TI. Lingkungan bisnis meliputi lingkungan bisnis internal dan lingkungan bisnis eksternal. Demikian juga dengan lingkungan SI/TI yang meliputi lingkungan SI/TI internal dan eksternal. Dengan pemahaman yang mendalam terhadap kondisi saat ini, maka dapat ditentukan strategi SI, strategi TI dan strategi SI/TI di masa mendatang secara tepat.

Pengolahan dan analisis data menggunakan analisis rantai nilai (value chain analysis), analisis five competitive forces model, analisis Mcfarlan strategic grid dan analisis SWOT (strength, weakness, opportunities and threats). Analisis value chain digunakan untuk memetakan seluruh proses kerja yang terjadi dalam organisasi menjadi dua kategori aktivitas, yaitu aktivitas utama dan aktivitas pendukung.

Porter menyatakan bahwa ada lima kekuatan bersaing yang memengaruhi kesuksesan suatu industri, yaitu ancaman pendatang baru, tingkat rivalitas diantara para pesaing, produk substitusi, kekuatan tawar-menawar pembeli dan kekuatan tawar-menawar pemasok (Riky \& Mustamu, 2014). Pemetaan analisis Mcfarlan strategic grid bertujuan mempermudah operasional pihak manajemen untuk mengambil keputusan dalam menentukan posisi sistem TI operasional perusahaan di dalam kuadran tersebut, serta keinginan operasional perusahaan dalam menentukan ke arah mana SI akan dipenuhi menurut kapabilitas dan visi serta misi operasional perusahaan di masa mendatang (Olivia, 2016).

Analisis SWOT dibagi menjadi tiga tahap penentuan strategi utama, yaitu tahap input, pencocokan dan keputusan. Tahap input yaitu identifikasi faktor internal dan eksternal, pemberian bobot setiap faktor dan pembentukan matriks IFE (Internal Factor Evaluation) dan EFE (External Factor Evaluation). Tahap pencocokan merupakan tahapan menghasilkan alternatif strategi dengan memadukan faktor-faktor internal dan eksternal yang telah dihasilkan pada tahap input. Pada tahap pencocokan ini digunakan alat analisis matriks IE dan SWOT. Matriks IE merupakan alat menentukan posisi suatu perusahaan pada internal dan eksternal. Tujuan penggunaan matriks ini untuk memperoleh strategi bisnis yang lebih detail (David, 2009). Matriks SWOT didasarkan pada asumsi bahwa strategi yang efektif akan memaksimalkan 
kekuatan dan peluang, serta meminimalkan kelemahan dan ancaman. Kombinasi faktor-faktor internal dan eksternal dalam matriks SWOT terdiri atas strategi kekuatan-peluang (S-O), strategi kelemahan-peluang (W-O), strategi kelemahan-ancaman (W-T) dan strategi kekuatanancaman (S-T). Analisis matriks SWOT akan menghasilkan beberapa alternatif strategi yang dapat dipilih perusahaan dalam mengembangkan usahanya (Soesilo, 2000). Tahap terakhir adalah dalam formulasi strategi pengambilan keputusan. Analisis yang digunakan pada tahap ini adalah matriks QSP (Quantitive Strategic Planning). David (2006) menyatakan bahwa QSPM adalah alat yang memungkinkan penyusunan strategi untuk mengevaluasi alternatif strategi secara objektif, berdasarkan faktor keberhasilan kunci internal dan eksternal yang telah diidentifikasi sebelumnya (David, 2006).

\section{HASIL DAN PEMBAHASAN}

Visi perusahaan menjunjung tinggi kepercayaan konsumen akan produk yang sehat dan bersih. Misinya menciptakan produk tanpa Monosodium Glutamat (MSG) dan pengawet sintetis. Sumberdaya dalam perusahaan terdiri dari divisi produksi 12 orang, distribusi dan logistik tiga orang, marketing dua orang, keuangan dua orang. Karyawan tetap dalam usaha ini sebanyak 19 orang dan tenaga kerja lepas untuk pengemasan saat jumlah produksi tinggi.

\section{Analisis Rantai Nilai}

Hasil analisis value chain pada UD Vier 57 Sehat Bergizi terhadap proses kerja pada masingmasing unit kerja ditunjukkan pada Gambar 1.

\section{Five Competitive Forces Porter}

1. Ancaman pendatang baru

Ancaman pendatang baru bagi UD Vier 57 Sehat Bergizi adalah harga lebih rendah, merek lebih dikenal konsumen, modal yang lebih besar, lokasi usaha yang baik dan peraturan perizinan yang lengkap. Pendatang baru yang menjadi ancaman bagi UD Vier 57. Sehat Bergizi adalah Tiara Food dan Kraukk. Kedua perusahaan tersebut memiliki metode pemasaran yang sama, yaitu sistem keagenan.

2. Daya tawar pemasok

Pemasok memiliki kekuatan penting yang sangat memengaruhi produksi UD Vier 57 Sehat Bergizi. Produk pemasok merupakan input penting bagi perusahaan dan sangat berpengaruh terhadap kebijakan impor daging nasional.

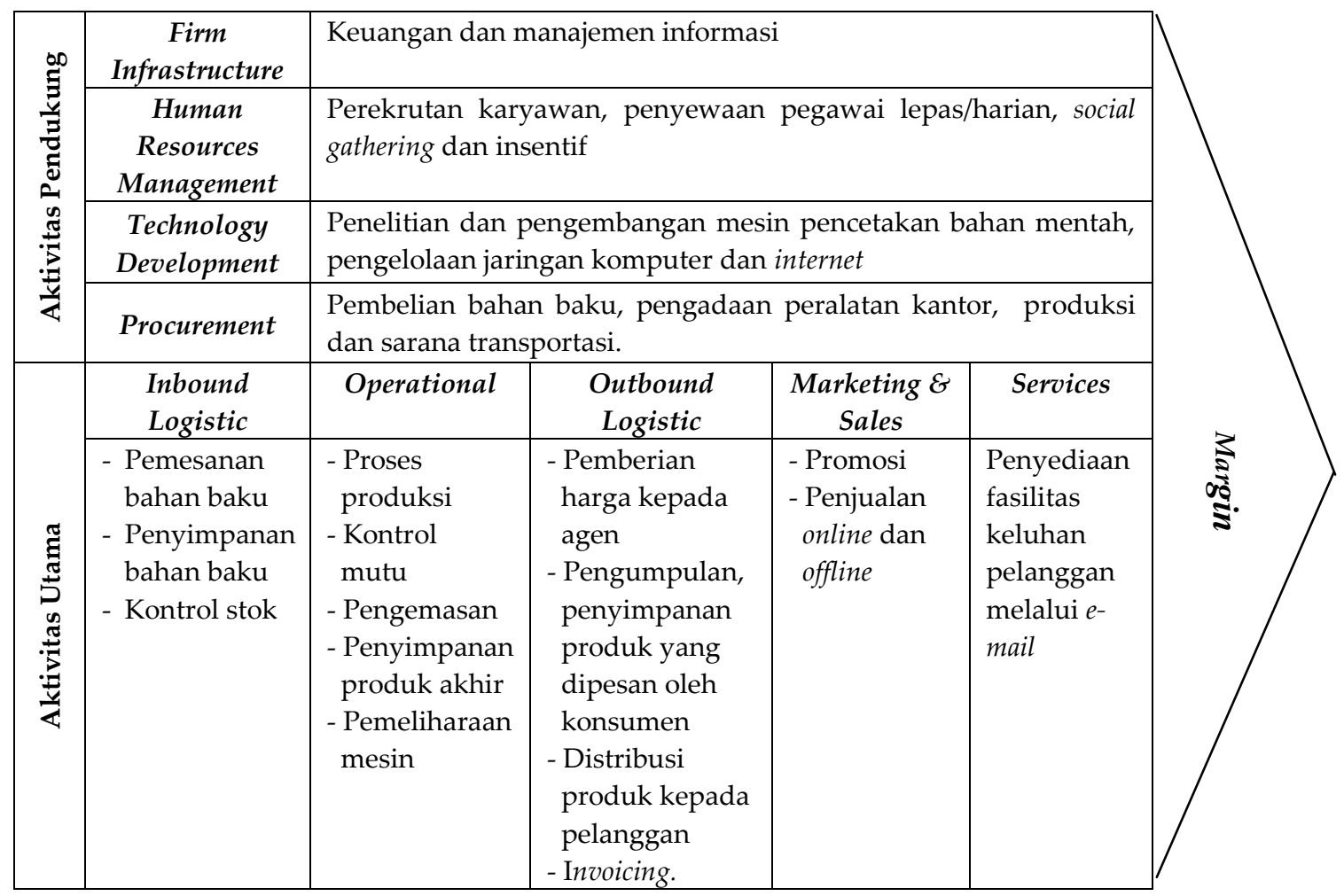

Gambar 1. Hasil analisis rantai nilai UD Vier 57 Sehat Bergizi 
3. Persaingan antar perusahaan sejenis

Persaingan antar perusahaa sejenis bagi UD Vier 57 Sehat Bergizi adalah adanya pesaing yang memiliki ragam produk olahan daging sapi. Perusahaan besar yang menjadi pesaing UD Vier 57 Sehat Bergizi adalah Farmhouse, Sumber Selera, CV Pelangi Anak, Fiesta dan Vida.

4. Daya tawar pembeli

Situasi yang membuat pembeli memiliki kekuatan dalam tawar-menawar perusahaan adalah jumlah produk yang dibeli, informasi produk yang lengkap dan mutu produk.

5. Ancaman produk substitusi

Ancaman produk substitusi bagi UD Vier 57 Sehat bergizi adalah harga yang lebih rendah dengan produk yang lebih menarik, kemudahan mendapatkan produk dan layanan yang lebih lengkap. Beberapa produk substitusi adalah sosis dan tahu baso.

\section{Penerapan SI dan TI}

Analisis diteliti dari sisi lingkungan internal maupun eksternal, khususnya di bidang SI/TI yang dimulai dari SI yang ada saat ini baik perangkat keras (hardware) yang umum dipakai, perangkat lunak (software) berupa aplikasiaplikasi yang ada di organisasi pada umumnya, sistem operasi utama yang digunakan, serta kondisi infrastrukturnya. Identifikasi terhadap analisis lingkungan internal dan eksternal SI/TI perusahaan dijabarkan sebagai berikut:

a. Perangkat Keras (Hardware)

Perangkat keras yang digunakan oleh perusahaan untuk menunjang kegiatan operasional kantor adalah dua unit Personal Computer dengan spesifikasi processor core i5. RAM 4 GB, Hard Disk 500 GB, VGA 2 GB, satu unit laptop dan satu unit PC Tablet.

b. Perangkat Lunak (Software)

Aplikasi yang digunakan oleh perusahaa untuk menunjang operasional kantor dan produksi adalah Adobe Photoshop, Corel Draw, MS. Office (Excel, Power Point, Words) dan aplikasi keuangan.

c. Sistem Operasi

Sistem operasi yang digunakan pada PC perusahaan adalah Windows 7 Ultimate. Sistem operasi laptop menggunakan Windows 10 Home Single Language.

d. Infrastruktur

Jaringan internet pada kantor UD Vier 57 Sehat bergizi menggunakan Wireless (LAN) atau kadang disingkat dengan (WLAN). WLAN saat ini disinonimkan dengan Wireless Fidelity atau yang sering ditulis dengan Wi-Fi. Wi-Fi adalah sebuah sistem komunikasi data fleksibel yang dapat diaplikasikan sebagai ekstensi ataupun sebagai alternatif pengganti untuk jaringan LAN kabel. Teknologi ini menggunakan frekuensi radio, mengirim dan menerima data melalui media udara dengan meminimalisasi kebutuhan akan sambungan kabel. Dengan begitu, wireless LAN telah dapat mengkombinasikan antara konektivitas data dengan mobilitas pengguna (Wongkar, 2015).

\section{Renstra SI/TI}

Renstra SI/TI mempelajari pengaruh SI/TI terhadap kinerja bisnis dan kontribusi bagi organisasi dalam memilih langkah-langkah strategis (Ward dan Peppard, 2002). Berdasarkan analisis lingkungan bisnis dan SI/TI internal dan eksternal perusahaan, maka rekomendasi Renstra sebagai berikut:

1. Strategi Bisnis

Strategi SI bisnis mencakup bagaimana setiap divisi memanfaatkan SI untuk mencapai sasaran bisnisnya (visi dan misi), portfolio aplikasi dan gambaran arsitektur informasi. UD Vier 57 Sehat Bergizi memiliki sebuah situs website tersendiri dengan alamat http://www.baso57kuahsehat.com. Website ini merupakan pintu gerbang maya bagi pihak luar/konsumen yang ingin mencari informasi mengenai produk atau profil perusahaan. Informasi yang didapat oleh end user saat ini adalah latar belakang perusahaan, varian produk, daftar agen, pendaftaran menjadi agen baru, cara pembayaran dan alamat, serta kontak perusahaan. Website ini perlu dikembangkan untuk memudahkan konsumen bertransaksi, baik dalam pemesanan maupun pembayaran, sehingga margin perusahaan dapat meningkat.

\section{Strategi TI}

Strategi TI disini mencakup kebijakan dan strategi bagi pengelolaan teknologi dan sumber daya, sehingga strategi TI ini menitikberatkan pada bagaimana merencanakan dan menerapkan sumber daya TI yang didukung oleh SDM handal yang sifatnya dinamis dalam mengikuti perkembangan internal dan eksternal suatu perusahaan.

\section{Strategi Managemen SI/TI}

Kebijakan mengenai pemeliharaan dan pengembangan SI/TI yang mendukung kebutuhan organisasi dinamis dengan memperhatikan trend SI/TI mulai pemeliharaan hardware, software 
dan infrastruktur, sehingga peran SI/TI disini dapat menjadi nilai tambah.

\section{Portofolio Aplikasi}

Model pemetaan Mcfarlan Strategic Grid bertujuan menganalisis suatu aplikasi atau SI di suatu operasional perusahaan berdasarkan kondisi saat ini, kondisi yang direncanakan dan aplikasi-aplikasi yang dianggap berpotensi dalam menunjang bisnis operasional perusahaan (Mcfarlan et al, 1983). Penggunaan SI pada UKM UD Vier 57 Sehat bergizi saat ini dapat dilihat pada Tabel 2.

Tabel 2. SI UD Vier 57 Sehat bergizi saat ini

\begin{tabular}{ll}
\hline \multicolumn{1}{c}{ Aplikasi } & \multicolumn{1}{c}{ Pemanfaatan } \\
\hline Website & Sarana informasi terkait harga, varian \\
www.baso57kua & $\begin{array}{l}\text { produk, kontak dan alamat agen dan } \\
\text { ksehat.com }\end{array}$ \\
\hline Microsoft Office & $\begin{array}{l}\text { Pendukn pelanggan } \\
\text { produksi }\end{array}$ \\
\hline Adobe Photoshop & Pendukung administrasi kantor dan \\
dan Corel Draw & pemasaran produk \\
\hline FreshBooks & Pengelolaan keuangan \\
\hline Infor Supply Chain & Pengelolaan bahan baku masuk \\
Management & sampai distribusi produk \\
\hline
\end{tabular}

Berdasarkan pemetaan fungsi dari analisis value chain dan kebutuhan SI, maka dapat dikelompokkan pada Tabel 3. Semua sistem yang ada kemudian dipetakan ke dalam matriks Mcfarlan's grid untuk dijadikan portofolio aplikasi sistem informasi masa depan (Tabel 4). Portofolio aplikasi masa depan merupakan penjabaran dari aplikasi yang akan digunakan oleh perusahaan di masa mendatang, untuk menghasilkan informasi yang dibutuhkan oleh perusahaan dalam mendukung kegiatan bisnis perusahaan. Selain itu, portofolio aplikasi digunakan sebagai dasar untuk mengidentifikasi kebutuhan perusahaan terhadap perangkat teknologi masa mendatang.

\section{Analisis Matriks IFE}

Analisis matriks IFE diperoleh skor tertinggi faktor kekuatan cita rasa yang enak (skor 0,632) dan mutu produk yang bebas bahan pengawet dan MSG dengan skor 0,600. Skor terendah pada faktor kekuatan adalah inovasi produk, 0,343. Pada faktor kelemahan, skor tertinggi adalah modal, 0,248. Skor terendah pada faktor kelemahan adalah promosi masih kurang $(0,164)$. Total skor matriks IFE 3,098, menunjukkan kekuatan yang dimiliki UD Vier 57 Sehat
Bergizi dapat mengatasi kelemahan dengan cukup baik (Tabel 5).

Tabel 3. Rekomendasi SI UD Vier 57 Sehat bergizi mendatang

\begin{tabular}{ll}
\hline \multicolumn{1}{c}{ Aplikasi } & \multicolumn{1}{c}{ Pemanfaatan } \\
\hline $\begin{array}{l}\text { Website: } \\
\text { www.baso57kuahsehat. }\end{array}$ & $\begin{array}{l}\text { Sarana informasi terkait } \\
\text { harga, varian produk, kontak } \\
\text { dan alamat agen, serta } \\
\text { transaksi penjualan }\end{array}$ \\
\hline Microsoft Office & $\begin{array}{l}\text { Pendukung administrasi } \\
\text { kantor dan produksi }\end{array}$ \\
\hline Adobe Photoshop dan & $\begin{array}{l}\text { Pendukung administrasi } \\
\text { kantor dan pemasaran } \\
\text { porel Draw }\end{array}$ \\
\hline FreshBooks & Pengelolaan keuangan \\
\hline E-Commerce & Pemasaran produk \\
\hline $\begin{array}{l}\text { Infor Supply Chain } \\
\text { Management }\end{array}$ & $\begin{array}{l}\text { Pengelolaan bahan baku ma- } \\
\text { suk sampai distribusi produk }\end{array}$ \\
\hline Customer Relationship & Manajemen pelanggan meli- \\
Management (CRM) & $\begin{array}{l}\text { puti keluhan dan kebutuhan } \\
\text { pelanggan }\end{array}$ \\
\hline
\end{tabular}

Tabel 4. Rekomendasi portofolio aplikasi mendatang

\begin{tabular}{ll}
\hline \multicolumn{1}{c}{ Strategic } & \multicolumn{1}{c}{ High Potential } \\
\hline E-Commerce & $\begin{array}{l}\text { Customer Relationship } \\
\text { Management (CRM) }\end{array}$ \\
\hline Website: & Microsoft Office \\
FreshBooks & Adobe Photoshop \\
Infor Supply Chain & Corel Draw \\
Management & \\
\hline \multicolumn{1}{c}{ Key Operational } & Support \\
\hline
\end{tabular}

Tabel 5. Hasil IFE UD Vier 57 Sehat Bergizi

\begin{tabular}{lccc}
\hline \multicolumn{1}{c}{ Faktor Internal } & $\begin{array}{c}\text { Bobot } \\
(\mathbf{a})\end{array}$ & $\begin{array}{c}\text { Peringkat } \\
(\mathbf{b})\end{array}$ & $\begin{array}{c}\text { Skor } \\
(\mathbf{a x b})\end{array}$ \\
\hline $\begin{array}{l}\text { Kekuatan } \\
\text { 1. Cita rasa enak }\end{array}$ & 0,158 & 4,00 & 0,632 \\
$\begin{array}{l}\text { 2. Mutu produk bahan } \\
\text { baku bebas pengawet }\end{array}$ & 0,150 & 4,00 & 0,600 \\
$\quad$ dan MSG & & & \\
$\begin{array}{l}\text { 3. Cara memasak } \\
\quad \text { instan (cepat saji) }\end{array}$ & 0,127 & 4,00 & 0,508 \\
$\begin{array}{l}\text { 4. Harga terjangkau } \\
\text { 5. Inovasi produk }\end{array}$ & 0,131 & 3,00 & 0,393 \\
\hline $\begin{array}{l}\text { Kelemahan } \\
\text { 1. Modal }\end{array}$ & 0,098 & 3,50 & 0,343 \\
$\begin{array}{l}\text { 2. Teknologi informasi } \\
\text { 3. Promosi }\end{array}$ & 0,124 & 2,00 & 0,248 \\
\hline \multicolumn{2}{c}{ Total } & 2,00 & 0,210 \\
\hline
\end{tabular}

\section{Analisis Matriks EFE}

Hasil analisis matriks EFE dapat diketahui skor tertinggi pada peluang adalah bertambahnya agen dengan skor 0,512. Skor terendah pada 
peluang adalah permintaan pasar untuk produk olahan daging sapi dengan skor 0,261. Pada ancaman, skor tertinggi 0,260 terdapat pada kebijakan impor daging. Skor terendah pada brand image produk dan keberadaan pesaing usaha produk olahan daging sapi yang beragam dengan skor 0,064. Total skor matriks EFE 2,629 menunjukkan bahwa UD Vier 57 Sehat Bergizi cukup baik dalam merespon peluang dan meminimalisasi ancaman (Tabel 6).

\section{Analisis Matriks IE}

Nilai skor total kombinasi matriks IFE dan EFE digunakan untuk mengetahui posisi perusahaan. Berdasarkan kombinasi skor IFE dan EFE didapatkan matriks IE. Skor matriks IE menunjukkan UD Vier 57 Sehat Bergizi pada posisi kuadran IV, yaitu, grow and build. Strategi yang cocok untuk kuadran ini adalah strategi intensif (penetrasi pasar, pengembangan pasar dan pengembangan produk) atau integratif (integrasi ke depan, belakang dan horizontal). Matrik IE dapat dilihat pada Gambar 2.

\section{Analisis Matriks SWOT}

Matriks SWOT dapat menggambarkan bagaimana peluang dan ancaman eksternal yang dihadapi UD Vier 57 Sehat Bergizi dapat disesuaikan dengan kekuatan dan kelemahan internal. Matriks ini menghasilkan empat sel kemungkinan alternatif strategi, yaitu strategi S$\mathrm{O}$, strategi $\mathrm{W}-\mathrm{O}$, strategi $\mathrm{W}-\mathrm{T}$, dan strategi S-T seperti disajikan pada Gambar 3.

\section{Analisis Matriks QSPM}

Dari hasil analisis Matriks IE dan Matriks SWOT, diperoleh alternatif strategi yang akan diterapkan oleh UD. Vier 57 Sehat Bergizi. Untuk menentukan prioritas strategi yang paling utama bagi perusahaan, dilakukan analisis Matriks QSP. Alternatif-alternatif strategi dimaksud adalah:

1. Memperluas pemasaran produk yang ada saat ini di pasar baru

2. Meningkatkan pelayanan pelanggan

3. Merekrut atau mengatur tugas personil untuk mengelola TI

4. Menggunakan bahan baku lokal

5. Menjaga dan mempertahankan mutu produk

6. Meningkatkan upaya pemasaran secara intensif dan efisien melalui media online (ecommerce)

Tabel 6. Hasil EFE UD Vier 57 Sehat Bergizi

\begin{tabular}{|c|c|c|c|}
\hline Faktor Eksternal & $\begin{array}{l}\text { Bobot } \\
\text { (a) }\end{array}$ & $\begin{array}{l}\text { Peringkat } \\
\text { (b) }\end{array}$ & $\begin{array}{l}\text { Skor } \\
(\mathbf{a x b})\end{array}$ \\
\hline \multicolumn{4}{|l|}{$\begin{array}{ll}\text { Peluang } \\
\end{array}$} \\
\hline 1. Bertambahnya agen & 0,128 & 4,00 & 0,512 \\
\hline $\begin{array}{l}\text { 2. Trend makanan instan } \\
\text { atau cepat saji }\end{array}$ & 0,104 & 3,50 & 0,364 \\
\hline $\begin{array}{l}\text { 3. Kesadaran konsumen } \\
\text { mengenai makanan } \\
\text { sehat }\end{array}$ & 0,103 & 3,50 & 0,361 \\
\hline 4. Penjualan online & 0,087 & 4,00 & 0,348 \\
\hline $\begin{array}{l}\text { 5. Permintaan pasar } \\
\text { untuk produk olahan } \\
\text { daging sapi }\end{array}$ & 0,087 & 3,00 & 0,261 \\
\hline $\begin{array}{l}\text { 6. Informasi produk yang } \\
\text { lengkap }\end{array}$ & 0,064 & 3,50 & 0,224 \\
\hline \multicolumn{4}{|l|}{ Ancaman } \\
\hline $\begin{array}{l}\text { 1. Kebijakan impor bahan } \\
\text { baku }\end{array}$ & 0,130 & 2,00 & 0,260 \\
\hline 2. Brand image produk & 0,087 & 1,00 & 0,064 \\
\hline $\begin{array}{l}\text { 3. Layanan perusahaan } \\
\text { yang lengkap }\end{array}$ & 0,064 & 1,50 & 0,131 \\
\hline $\begin{array}{l}\text { 4. Kemudahan } \\
\text { mendapatkan produk }\end{array}$ & 0,084 & 2,00 & 0,168 \\
\hline $\begin{array}{l}\text { 5eberadaan pesaing } \\
\text { usaha produk olahan } \\
\text { daging sapi yang } \\
\text { beragam }\end{array}$ & 0,064 & 1,00 & 0,064 \\
\hline Total & & & 2,629 \\
\hline
\end{tabular}

\section{Skor Total IFE}

\begin{tabular}{|c|c|c|c|c|}
\hline & & $\begin{array}{l}\text { Kuat } \\
4.0\end{array}$ & $\begin{array}{l}\text { Rataan } \\
3.0\end{array}$ & $\begin{array}{l}\text { Lemah } \\
2.0\end{array}$ \\
\hline & 4.0 & I & II & III \\
\hline Skor & Tinggi & $\begin{array}{c}\text { Grow and } \\
\text { Build }\end{array}$ & $\begin{array}{c}\text { Grow and } \\
\text { Build }\end{array}$ & $\begin{array}{l}\text { Hold and } \\
\text { Maintain }\end{array}$ \\
\hline Total & 3.0 & IV & $\mathrm{V}$ & VI \\
\hline EFE & Rataan & $\begin{array}{c}\text { Grow and } \\
\text { Build }\end{array}$ & $\begin{array}{l}\text { Hold and } \\
\text { Maintain }\end{array}$ & $\begin{array}{c}\text { Harvest or } \\
\text { Divest }\end{array}$ \\
\hline & $\begin{array}{l}2.0 \\
\text { Rendah }\end{array}$ & $\begin{array}{c}\text { VII } \\
\text { Harvest or } \\
\text { Divest }\end{array}$ & $\begin{array}{c}\text { VIII } \\
\text { Harvest or } \\
\text { Divest }\end{array}$ & $\begin{array}{c}\text { IX } \\
\text { Harvest or } \\
\text { Divest }\end{array}$ \\
\hline
\end{tabular}

Gambar 2. Hasil analisis Matriks IE 


\begin{tabular}{|c|c|c|}
\hline Eksternal & $\begin{array}{l}\text { Kekuatan (S) } \\
\text { 1. Inovasi produk } \\
\text { 2. Mutu produk karena } \\
\text { kandungan bahan baku bebas } \\
\text { pengawet dan MSG } \\
\text { 3. Harga terjangkau } \\
\text { 4. Cita rasa yang enak } \\
\text { 5. Cara memasak instan (cepat } \\
\text { saji) }\end{array}$ & $\begin{array}{l}\text { Kelemahan (W) } \\
\text { 1. Promosi belum } \\
\text { optimal } \\
\text { 2. Teknologi informasi } \\
\text { belum optimal } \\
\text { 3. Keterbatasan pada } \\
\text { modal }\end{array}$ \\
\hline $\begin{array}{l}\text { Peluang (O) } \\
\text { 1. Permintaan pasar yang stabil untuk produk } \\
\text { olahan daging sapi } \\
\text { 2. Bertambahnya agen } \\
\text { 3. Trend makanan instan atau cepat saji } \\
\text { 4. Penjualan online } \\
\text { 5. Kesadaran konsumen mengenai makanan } \\
\text { sehat } \\
\text { 6. Informasi produk yang lengkap }\end{array}$ & $\begin{array}{l}\text { Strategi SO } \\
\text { 1. Memperluas pemasaran } \\
\text { produk yang ada saat ini } \\
\text { pada pasar baru } \\
\text { (S1,S2,S4,S5;O1,O2,O3,O4,O5) } \\
\text { 2. Meningkatkan pelayanan } \\
\text { pelanggan } \\
(\mathrm{S} 1, \mathrm{~S} 2, \mathrm{~S} 3, \mathrm{~S} 4, \mathrm{~S} 5 ; \mathrm{O} 1, \mathrm{O} 2, \mathrm{O} 3, \mathrm{O} 4, \\
\mathrm{O} 5, \mathrm{O} 6)\end{array}$ & $\begin{array}{l}\quad \text { Strategi WO } \\
\text { 1. Merekrut atau } \\
\text { mengatur tugas } \\
\text { personil untuk } \\
\text { mengelola teknologi } \\
\text { informasi } \\
\text { (W1,W2,W3;O1,O2,O } \\
\text { 3,O4,O5,O6) }\end{array}$ \\
\hline $\begin{array}{l}\text { Ancaman (T) } \\
\text { 1. Kebijakan impor bahan baku } \\
\text { 2. Keberadaan pesaing usaha produk olahan } \\
\text { daging sapi yang beragam } \\
\text { 3. Pemasaran lebih didominasi oleh perusahaan } \\
\text { besar dengan merek dagang yang lebih dikenal } \\
\text { oleh konsumen } \\
\text { 4. Kemudahan mendapatkan produk pesaing } \\
\text { 5. Layanan perusahaan pesaing yang lebih } \\
\text { lengkap }\end{array}$ & $\begin{array}{l}\text { Strategi ST } \\
\text { 1. Menggunakan bahan baku } \\
\text { lokal (S1,S2,S4;T1) } \\
\text { 2. Menjaga dan } \\
\text { mempertahankan mutu } \\
\text { produk } \\
\text { (S1,S2,S3,S4,S5;T2,T3,T4,T5) }\end{array}$ & \begin{tabular}{l}
\multicolumn{1}{c}{ Strategi WT } \\
1. Meningkatkan upaya \\
pemasaran secara \\
intensif dan efisien \\
melalui media online \\
$($ e-commerce $)$ \\
$(\mathrm{W} 1, \mathrm{~W} 2 ; \mathrm{T} 2, \mathrm{~T} 3, \mathrm{~T} 4, \mathrm{~T} 5)$
\end{tabular} \\
\hline
\end{tabular}

Gambar 3. Hasil analisis Matriks SWOT

Tabel 7. Urutan prioritas strategi Matriks QSP

\begin{tabular}{lcc}
\hline \multicolumn{1}{c}{ Alternatif Strategi } & Nilai TAS & Prioritas \\
\hline 1. Meningkatkan upaya pemasaran secara intensif dan efisien melalui & 6.842 & I \\
media online (e-commerce) & & 6.667 \\
2. Menjaga dan mempertahankan mutu produk & 6.649 & II \\
3. Meningkatkan pelayanan pelanggan & 6.517 & IV \\
4. Memperluas pemasaran produk yang ada saat ini pada pasar baru & V \\
5. Merekrut atau mengatur tugas personil untuk mengelola teknologi & 6.431 & \\
informasi & 2.506 & VI \\
6. Menggunakan bahan baku lokal & & \\
\hline
\end{tabular}

Berdasarkan hasil perhitungan dalam matriks QSP, diperoleh strategi paling tepat adalah meningkatkan upaya pemasaran secara intensif dan efisien melalui media online dengan total TAS tertinggi 6.842. Untuk lebih jelasnya tentang urutan prioritas strategi dari hasil matriks QSP dapat dilihat pada Tabel 7.

\section{Implikasi Manajerial}

Implikasi manajerial dalam pengembangan usaha di UD. Vier 57 Sehat Bergizi dapat dirumuskan dalam beberapa langkah strategi berikut:
1. Meningkatkan pengenalan merek produk untuk menjaga eksistensi usaha baso 57 kuah sehat dengan komunikasi pemasaran. Peningkatan komunikasi pemasaran dapat dilakukan melalui promosi pada media sosial yang sekarang menjadi media promosi yang sangat efektif dan murah (misal dengan berlangganan fanpage, instagram atau twitter).

2. Memperluas jaringan pemasaran dengan melakukan penetrasi pasar, misalnya membuat ritel gerai.

3. Meningkatkan pemanfaatan TI secara maksimal dengan menentukan karyawan sebagai 
admin SI/TI untuk mengelola pemasaran produk.

\section{KESIMPULAN}

Dari analisis lingkungan bisnis internal dan eksternal, lingkungan SI/TI perusahaan dan penyusunan strategi mengenai Renstra SI yang telah dilakukan pada UD. Vier 57 Sehat Bergizi, dapat diambil beberapa simpulan sebagai berikut:

a. Renstra SI/TI dapat menciptakan strategi SI/TI yang selaras dengan tujuan usaha bisnis Baso 57 Kuah Sehat. Penerapan dan pemanfaatan SI dalam usaha ini sudah cukup baik.

b. Arsitektur aplikasi baru yang diusulkan dua aplikasi untuk keperluan pemasaran dan pengelolaan pelanggan yaitu e-commerce dan CRM.

c. Analisis SWOT menghasilkan enam alternatif strategi yaitu memperluas pemasaran produk yang ada saat ini pada pasar baru, meningkatkan pelayanan pelanggan, merekrut atau mengatur tugas personil untuk mengelola TI, menggunakan bahan baku lokal, menjaga dan mempertahankan mutu produk dan meningkatkan upaya pemasaran secara intensif dan efisien melalui media online sebagai prioritas strategi utama yang dapat dijalankan oleh UD Vier 57 Sehat Bergizi adalah meningkatkan upaya pemasaran secara intensif dan efisien melalui media online.

\section{DAFTAR PUSTAKA}

[APJII] Asosiasi Penyelenggara Jasa internet Indonesia. 2015. Jumlah Kenaikan Pengguna internet di Indonesia.

David, FR. 2006. Manajemen Strategis Konsep. Edisi 10. Ichsan SB, Penerjemah. Jakarta (ID):
Salemba Empat. Terjemahan dari: Strategic Manajement.

Manajemen Strategis Konsep. Edisi 12. Dono S, Penerjemah. Jakarta (ID): Salemba Empat. Terjemahan dari: Strategic Manajement.

Guna, TH., G. Karyono. 2011. Perancangan Strategis Sistem Informasi dan Teknologi Informasi (SI/TI) pada Usaha Kecil Menengah (UKM) Berbasis e-business [internet]. [diunduh 2016 Sep 07]; Yogyakarta (ID).

Laudon, KC., JP. Laudon. 2004. Sistem Informasi Manajemen (Management Information Systems, Managing the Digital Firm). Terjemahan Philippus Erwin. (Edisi 8). Yogyakarta (ID): Andi.

Olivia, K. 2016. Perencanaan Strategis Sistem Informasi Sumber Daya Manusia pada STMIK Banjarbaru. Indonesian Journal on Networking and Security; 5(2):1-6.

Soesilo, IN. 2002. Manajemen Stratejik di Sektor Publik (Pendekatan Praktis),

Turban, E. 2005. Decision Support Systems and Intelligent Systems. $7^{\text {th }}$ Ed. New Jersey (US): Pearson Education.

Ward, J., J. Peppard. 2002. Strategic Planning for Information Systems, 3rd ed. England (GB): John Wiley \& Sons.

Jilid II. Jakarta (ID): Universitas Indonesia. Wongkar, S., S. Alicia, N. Xaverius. 2015. Analisa Implementasi Jaringan Internet dengan Menggabungkan Jaringan LAN dan WLAN di Desa Kawangkoan Bawah wilayah Amurang II. Journal Teknik Elektro dan Komputer, 4(6):62-68.

Yunus, S. 2011. Jurnalistik Terapan. Bogor (ID): Ghalia Indonesia. 